\title{
Almitrine bismesylate and oxygen therapy in hypoxic cor pulmonale
}

Timothy W Evans, Jessica Tweney, Judith C Waterhouse, Jonathon Nichol, Andrew J Suggett, Peter Howard

\begin{abstract}
The effect of oral treatment with the thiazine derivative almitrine bismesylate was studied in 28 patients with chronic obstructive pulmonary disease and arterial hypoxaemia receiving long term domiciliary oxygen therapy in a placebo controlled, double blind crossover trial. The initial treatment was given for three months and the second for two months. Because almitrine had an unexpectedly prolonged washout effect crossover analysis could not be performed; data from the placebo treatment administered in the second arm of the trial were used to calculate the half life of almitrine. Nine patients were withdrawn from the
\end{abstract} study (5 almitrine, 4 placebo). Patients' tolerance of the drug was good. The estimated plasma half life of almitrine was 20.5 days, considerably longer than previously reported. Almitrine caused a significant improvement in arterial oxygen tension $\left(\mathrm{Pao}_{2}\right)$ with a mean maximum increase of $0.7 \mathrm{kPa}$ at a plasma concentration of $500 \mathrm{ng} / \mathrm{ml}$. Higher plasma concentrations were not associated with any further increase in $\mathbf{P a O}_{2}$. There was no significant effect on arterial carbon dioxide tension $\left(\mathrm{PaCO}_{2}\right)$. In a second, acute study at the end of each arm of the chronic trial nine patients were subjected to increasing oxygen delivery rates $(2,4$, and $61 / \mathrm{min})$ for 90 minutes or until blood gas concentrations plateaued. Almitrine increased $\mathrm{PaO}_{2}$ in a dose dependent fashion at all delivery rates, but the effect diminished as $\mathrm{PaO}_{2}$ approached normoxic levels. There was no significant effect on $\mathrm{PaCO}_{2}$. Almitrine treatment results in a significant improvement in $\mathrm{PaO}_{2}$ over that achieved by oxygen alone, an effect that diminishes at high flow rates. Whether this is of clinical benefit is not known. In view of the prolonged half life revised dosage schedules are required.

Academic Division of Medicine, University of Sheffield, Royal Hallamshire Hospital, Sheffield

T W Evans

J Tweney

J W Waterhouse

J Nichol

A J Suggett

P Howard

Address for reprint requests: Dr P Howard, M Floor,
Royal Hallamshire Hospital, Sheffield S10 2JF.

Accepted 2 October 1989 patients die within five years of the onset of peripheral oedema. ${ }^{12}$ Long term domiciliary oxygen therapy provided at flow rates sufficient to raise $\mathrm{PaO}_{2}$ to at least $8 \mathrm{kPa}$ for 15 or more hours a day is the only treatment that has been shown conclusively to improve survivial, ${ }^{34}$ but it is costly and onerous despite the use of oxygen concentrators. ${ }^{5}$ During acute exacerbations higher oxygen delivery rates may be needed to achieve an adequate $\mathrm{PaO}_{2}$ but this may cause an acute rise in $\mathrm{PaCO}_{2}$, probably resulting from a reduction in hypoxic drive and an aquired insensitivity to carbon dioxide. ${ }^{6}$

In theory, respiratory stimulants would be an attractive means of reducing the requirement for oxygen therapy during periods of stability. Such drugs might in addition prevent the rise in $\mathrm{PaCO}_{2}$ associated with the use of higher oxygen delivery rates during acute exacerbations. So far, however, respiratory stimulants have provided little convincing therapeutic benefit and many undesirable side effects. $^{?}$

Almitrine bismesylate, a triazine derivative, is a recently developed oral respiratory stimulant that differs from previous respiratory agonists by acting on peripheral chemoreceptors, principally the carotid body, to increase tidal volume. Oral doses of $50 \mathrm{mg}$ twice daily produce plasma concentrations of $200-400 \mathrm{ng} / \mathrm{ml}^{8}{ }^{8}$ Almitrine in clinical trials in patients with chronic obstructive lung disease has been shown to increase $\mathrm{PaO}_{2}$ by $0.5-1.2 \mathrm{kPa}$ and reduce $\mathrm{PaCO}_{2}$ by up to $1.0 \mathrm{kPa} .^{910}$

The aims of this study were therefore twofold: firstly, to evaluate the tolerance and efficacy of almitrine in improving arterial blood gas tensions in patients with hypoxic cor pulmonale already receiving long term domiciliary oxygen therapy; and, secondly, to assess the effects of almitrine on arterial gas tensions in patients with stable hypoxic cor pulmonale breathing oxygen at high delivery rates, to see if the drug would augment the increase in $\mathrm{PaO}_{2}$ while obviating any accompanying rise in $\mathrm{PaCO}_{2}$.

\section{Methods}

SUBJECTS

Seventeen men and 11 women (mean (SD) age $64.4(6 \cdot 2)$ years) with severe airways obstruction $\left(\mathrm{FEV}_{1} 0.62(0.28)\right.$ 1, FVC $\left.1.42(0.45) 1\right)$ were studied in the long term or "chronic" trial. All were hypoxaemic (arterial blood gases breathing air: $\mathrm{PaO}_{2} 6.2(0.9) \mathrm{kPa}, \mathrm{PaCO}_{2} 6.6$ $(0.8) \mathrm{kPa})$ and had had at least one documented episode of peripheral oedema. They were receiving controlled oxygen therapy by nasal cannula at $2 \mathrm{l} / \mathrm{min}$ from an oxygen concentrator or cylinders for a minimum of 15 hours a day. They had received oxygen at home for a mean of 49 (range 3-109) months. 
Nine of these patients $\left(\mathrm{PaO}_{2} 6.3(0 \cdot 7) \mathrm{kPa}\right.$, $\mathrm{PaCO}_{2} 6.5(0.06) \mathrm{kPa}$ breathing air) also participated in the second, "acute" study. In both studies the patient's usual medications were continued throughout; these were diuretics (23 patients), inhaled beta ${ }_{2}$ agonists (23 patients), ipratropium bromide (11 patients), oral beta agonists ( 5 patients), and oral theophylline ( 5 patients). Three patients were taking digoxin. All patients gave informed consent. The protocols were approved by the ethical committee of the Royal Hallamshire Hospital, Sheffield.

\section{TECHNIQUES}

In the chronic study all arterial blood samples were transported on ice in glass syringes. Control studies using arterial blood samples taken simultaneously and analysed immediately and after storage on ice for the same period showed no significant difference in $\mathrm{pH}, \mathrm{PaO}_{2}$, or $\mathrm{PaCO}_{2}$. In the acute study of the effects of almitrine during high oxygen delivery rates blood gas analyses were performed immediately. All samples were analysed with a Corning 170 instrument (Corning Medical and Scientific, Corning, Massachusetts). Spirometry was performed with a portable spirometer (Micro Medical Instruments, United Kingdom). Plasma almitrine concentrations were measured by gas-liquid chromatography to a sensitivity of $5 \mathrm{ng} / \mathrm{ml} .^{11}$

\section{STUDY PROTOCOLS}

\section{Chronic study}

The 28 patients were randomly allocated to receive placebo or almitrine $50 \mathrm{mg}$ twice daily in a double blind crossover trial. The first arm of the trial lasted for three months and the second only two months as the initial analysis showed that maximal changes in all variables had occurred in the first arm by 4 weeks.

Patients were visited at home on day 0 (pretreatment) and day 7, and at four week intervals thereafter throughout the trial. Subjects were also visited one to three weeks before entering the trial to check their clinical state and oxygen delivery system. At each visit oxygen therapy was continued from the previous night until after an arterial sample had been taken to ensure that gas tensions were measured during a period of stability. The oxygen delivery system was checked, patients were examined clinically, spirometry was performed, and venous blood samples were obtained for plasma almitrine estimation and routine haematological and biochemical tests. All blood samples were taken two to three hours after the drug was taken, when peak plasma almitrine concentrations would be expected. ${ }^{12}$

\section{Acute study}

The study was designed as a double blind, placebo controlled trial to be carried out on two study days at the end of each arm of the chronic trial, in which all nine patients also participated. During each study day patients were admitted to the respiratory function unit. An indwelling radial artery cannula was inserted and oxygen, initially at $2 \mathrm{l} / \mathrm{min}$, was administered via nasal cannulae. After a one hour stabilisation period, arterial samples were withdrawn for blood gas estimation at 15 minute intervals and analysed immediately until three consecutive measurements of $\mathrm{PaO}_{2}$ and $\mathrm{PaCO}_{2}$ varied by $0.5 \mathrm{kPa}$ or less. The last of these was recorded and a blood sample taken for almitrine estimation. The oxygen delivery rate was then adjusted. This procedure was repeated at flow rates of $41 / \mathrm{min}, 61 / \mathrm{min}$, and finally $2 \mathrm{l} / \mathrm{min}$ again. Patients continued their routine medications on the day of study, but refrained from taking beverages containing caffeine.

\section{DATA ANALYSİS}

Chronic study

Plasma almitrine analysis obtained after completion of the study showed that almitrine was detectable in the blood for several weeks after drug administration had been stopped. Thus patients given placebo tablets in the second arm of the trial had appreciable blood concentrations of almitrine for most or all of this time. Conventional analysis, comparing the blood gas results from each arm of the trial, was thus impossible. The blood gas results and plasma almitrine concentrations obtained from each home visit for the 19 patients completing the study were analysed. Arterial blood gas concentrations were related to plasma almitrine concentrations and curves with $95 \%$ confidence limits were fitted to the data by means of the GLIM statistical package and standard curve fitting techniques. ${ }^{1314} \mathrm{~F}$ ratios were generated to test the fit of these curves.

The half life of almitrine was estimated by fitting an exponential function to the plasma almitrine concentrations determined for the 10 patients who completed the second arm of the chronic study taking placebo. Dependence of half life on the initial drug concentration was tested by estimating the rate of elimination separately for each patient, and correlating these rates with the initial drug concentrations by the use of Spearman's rank coefficient. Values of less than 0.05 were considered significant.

\section{Acute study}

As almitrine had a longer half life than expected, the acute study similarly did not have a crossover design. The relation between arterial gas tensions and almitrine concentrations and oxygen flow rates was obtained by regressing blood gas tensions on the natural logarithms of the blood almitrine measurements, with oxygen flow treated as a factor with three levels. The regression modes included a separate term for the baseline value of each patient. F ratios were generated to test the significance of the estimated effects, which were considered significant at or below the 5\% level. Approximate $95 \%$ confidence intervals for the regression estimates (that is, the predicted mean value) were calculated for a patient with average baseline gas tensions, the GLIM statistical package ${ }^{1314}$ again being used. 
Figure 1 Plasma half life of almitrine for the 10 patients who completed the second arm of the study taking placebo. There was no correlation between half life and initial drug concentrations.

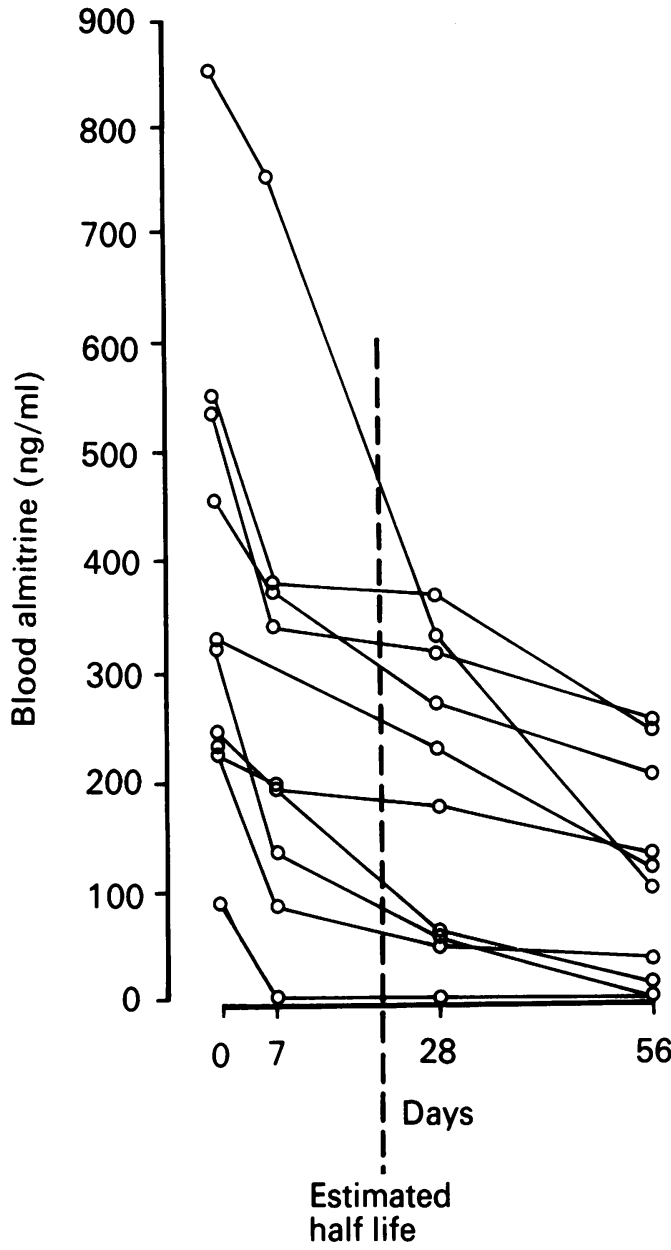

\section{Results}

CHRONIC STUDY

Withdrawals and side effects

Nineteen patients completed the study and nine withdrew or were withdrawn. There was no significant clinical or physiological difference between the two groups on entry to the trial. Five of the nine patients withdrawn were taking almitrine. Two withdrew before the first blood sample was taken for estimation of drug concentration, complaining of nausea, anorexia, insomnia, and non-specific malaise (one was subsequently found to be diabetic). A third was admitted with an exacerbation of cor pulmonale and died after only six days' treatment. A fourth withdrew after seven days, complaining of increased shortness of breath (the plasma almitrine concentration was 225 $\mathrm{ng} / \mathrm{ml}$ ) and a fifth complained of increased shortness of breath after 84 days, having had plasma almitrine concentrations of 200,677 , and $962 \mathrm{ng} / \mathrm{ml}$. Four patients withdrew when taking placebo (with almitrine levels of zero), three with increased breathlessness; the fourth
$\mathrm{PaO}_{2}, \mathrm{PaCO}_{2}(\mathrm{kPa})$

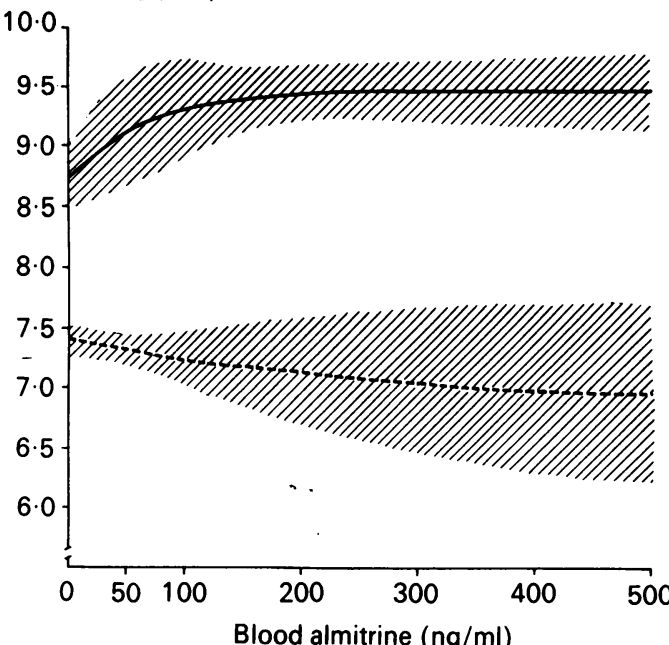

Figure 2 Relation of plasma almitrine concentration to arterial oxygen $\left(\mathrm{PaO}_{2}\right.$, solid line) and carbon dioxide tensions $\left(\mathrm{PaCO}_{2}\right.$, dotted line) with $95 \%$ confidence limits data from all home visits for 19 patients completing the trial, totalling 114 values. Four points on each curve for almitrine levels above $500 \mathrm{ng} / \mathrm{ml}$ are not shown.

was withdrawn on day 28 when carcinoma of the bronchus was diagnosed.

\section{Half life of almitrine}

Plasma concentration-time curves for 10 individuals after drug withdrawal and the estimated half life of the drug are shown in figure 1. Almitrine was detected in the blood of some patients for many days after active drug administration had ceased. The half life of almitrine was calculated as 20.5 days $(95 \%$ confidence limits 13, 43 days). There was no correlation between half life and initial drug concentration $(p>0.05)$.

\section{Arterial gas tensions}

Changes in $\mathrm{PaO}_{2}$ and $\mathrm{PaCO}_{2}$ during the breathing of domiciliary oxygen in relation to blood almitrine concentrations from the 19 patients completing the trial are shown in figure 2; each curve comprises 114 data points. Four values from each curve corresponded to almitrine concentrations above $500 \mathrm{ng} / \mathrm{ml}$ and are not shown. There was a curvilinear increase in $\mathrm{PaO}_{2}$ from a baseline concentration of $8.8(95 \%$ confidence limits $8.5,9.0) \mathrm{kPa}$ to a maximum of $9.5(9 \cdot 1,9.8) \mathrm{kPa}$ at a plasma almitrine concentration of $500 \mathrm{ng} / \mathrm{ml}$, beyond which the effect plateaued. There was a slight but statistically insignificant fall in $\mathrm{PaCO}_{2}$ from a baseline concentration of $7.4(7.2,7.6) \mathrm{kPa}$ to 7.0 $(6 \cdot 2,7 \cdot 8) \mathrm{kPa}$ at an almitrine concentration of $500 \mathrm{ng} / \mathrm{ml}$.

Mean (SD) stable arterial oxygen and carbon dioxide tensions $\left(\mathrm{PaO}_{2}, \mathrm{PaCO}_{2}\right)$ with oxygen flow rates of 2 , 4 , and $6 \mathrm{l} / \mathrm{min}$ in nine patients taking almitrine and nine taking placebo

\begin{tabular}{|c|c|c|c|c|c|c|c|}
\hline & \multicolumn{6}{|c|}{ Oxygen flow rate (l/min) } & \multirow{3}{*}{$\begin{array}{l}\text { Mean plasma } \\
\text { almitrine }(\mathrm{ng} / \mathrm{ml})\end{array}$} \\
\hline & \multicolumn{3}{|c|}{$\mathrm{PaO}_{2}(\mathrm{kPa})$} & \multicolumn{3}{|c|}{$\mathrm{PaCO}_{2}(\mathrm{kPa})$} & \\
\hline & $2 \star$ & 4 & 6 & $2^{\star}$ & 4 & 6 & \\
\hline Patients receiving almitrine & $\begin{array}{l}9.8(1.9) \\
9.7(1.9)\end{array}$ & $13 \cdot 2(3 \cdot 9)$ & $14 \cdot 6(3.9)$ & $\begin{array}{l}7.4(1.5) \\
7.4(1.6)\end{array}$ & $8.0(1 \cdot 7)$ & $8 \cdot 1(1 \cdot 8)$ & 268 \\
\hline Patients not receiving almitrine & $\begin{array}{r}10.7(2.0) \\
9.8(0.8)\end{array}$ & $15 \cdot 3(2 \cdot 3)$ & $15 \cdot 8(2 \cdot 9)$ & $\begin{array}{l}7.0(1 \cdot 2) \\
7 \cdot 4(1.4)\end{array}$ & $7 \cdot 7(1 \cdot 6)$ & $8 \cdot 2(1 \cdot 7)$ & 216 \\
\hline
\end{tabular}

«This flow rate was used twice. 


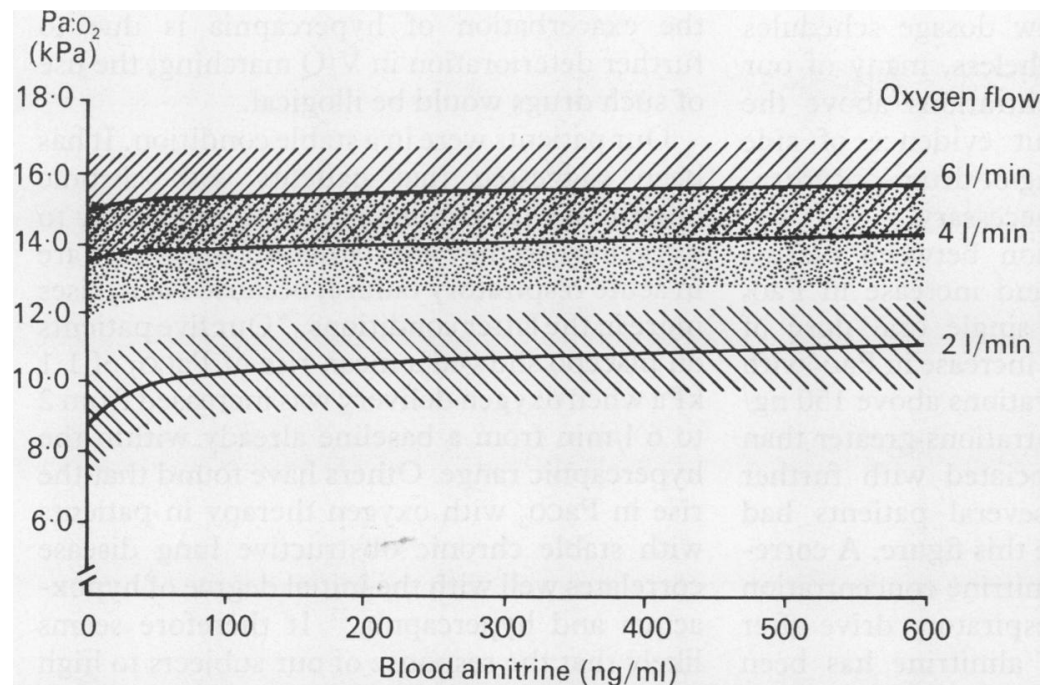

Figure 3 Estimated relation between plasma almitrine concentration and arterial oxygen tension $\left(\mathrm{PaO}_{2}\right)$ at oxygen delivery rates of 2,4 , and $6 \mathrm{l} / \mathrm{min}$, with $95 \%$ confidence bands for a patient with the average baseline $\mathrm{PaO}_{2}(8.4 \mathrm{kPa})$ measured while he was breathing oxygen at $2 \mathrm{l} / \mathrm{min}$.

\section{ACUTE STUDY}

The table shows mean values for the stable arterial gas tensions obtained at oxygen flow rates of $21 / \mathrm{min}$ (twice) and of 4 and $61 / \mathrm{min}$ and the mean plasma almitrine concentrations (three at each delivery rate from all patients). The latter varied very little in any subject, the blood samples having been taken over a few hours after 12 weeks (first study day) or eight weeks (second study day) of treatment. Data from the five patients taking placebo during the first arm of the chronic trial, who therefore had blood almitrine concentrations of zero when blood gases were estimated, are also shown. The estimated relation between blood almitrine concentration and the $\mathrm{PaO}_{2}$ at each of the three oxygen delivery rates is shown in figure 3. Only 67 of the total of 72 measurements are represented, as five almitrine concentrations were well over $600 \mathrm{ng} / \mathrm{ml} . \mathrm{PaO}_{2}$ increased significantly with increasing almitrine concentration $(p<0.01)$. At higher oxygen flow rates, however, the increase in $\mathrm{PaO}_{2}$ obtained from increasing doses of almitrine appeared to diminish. The estimated average increase in $\mathrm{PaO}_{2}$ obtained at a blood almitrine

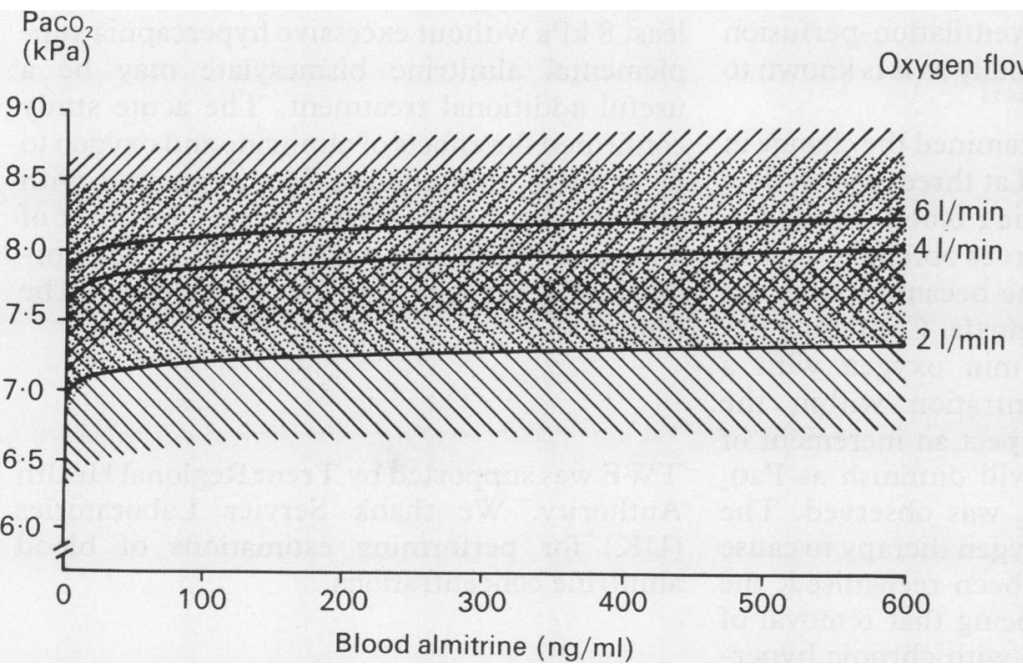

Figure 4 Estimated relation between plasma almitrine and carbon dioxide tension $\left(\mathrm{PaCO}_{2}\right)$ at oxygen delivery rates of 2,4 , and $6 \mathrm{l} / \mathrm{min}$, with $95 \%$ confidence bands shown for a patient with average baseline $\mathrm{PaCO}_{2}$ measured while he was breathing oxygen at 2 l/min. concentration of $250 \mathrm{ng} / \mathrm{ml}$ during the breathing of $21 / \mathrm{min}$ oxygen was $2 \cdot 2(95 \%$ confidence limits $1.0,3.4) \mathrm{kPa}$; at the same almitrine concentration the improvement in $\mathrm{PaO}_{2}$ with the breathing of 4 or $61 / \mathrm{min}$ was only $0.6(95 \%$ confidence limits $-0.7,1.9) \mathrm{kPa}$. The relation between $\mathrm{PaO}_{2}$ and blood almitrine concentration differed significantly between $21 / \mathrm{min}$ oxygen delivery and 4 and $6 \mathrm{l} / \mathrm{min}(\mathrm{p}<0.05)$.

The relation between $\mathrm{PaCO}_{2}$ and almitrine at the three oxygen flow rates is shown in figure 4 (67 measurements represented). Although there was a significant increase in $\mathrm{PaCO}_{2}$ at higher flow rates, there was no evidence that $\mathrm{PaCO}_{2}$ changed in relation to almitrine concentration, nor was there any suggestion of a different relation between $\mathrm{PaCO}_{2}$ and almitrine concentration at the different oxygen delivery rates.

\section{Discussion}

Almitrine was generally well tolerated by our subjects, whose most frequent complaints were increased breathlessness, nausea, and nonspecific malaise, which occurred equally in the groups having placebo and active treatment; only one patient had drug concentrations that were unacceptably high. Almitrine has been reported to cause breathlessness in normal subjects ${ }^{15}$ and patients with chronic obstructive lung disease, ${ }^{1617}$ with an increased incidence at higher drug concentrations; other trials, however, have reported a reduction in dyspnoea scores. ${ }^{9}$ The other withdrawals in the active treatment group were associated with malaise and gastrointestinal symptoms, as has been reported previously. ${ }^{15}$

The plasma half life of almitrine in our study (mean 20.5 days) is more than two weeks longer than that reported after three weeks' oral administration in healthy subjects, ${ }^{11}$ though a more prolonged half life has been reported in patients with chronic obstructive lung disease after several months' administration. ${ }^{10}$ Delayed clearance of almitrine may occur in patients with cirrhosis, but there was no evidence of hepatic dysfunction in any of our patients. Reasons for the long half life may be straightforward. Studies with radiolabelled drug show a very large volume of distribution $(15 \mathrm{l} / \mathrm{kg}$ in man), indicating extensive tissue uptake of almitrine. Plasma clearance of almitrine, which corresponds closely to hepatic clearance, is low at $4 \mathrm{ml} / \mathrm{min} / \mathrm{kg}{ }^{12}$ The combination of a large volume of distribution and a slow rate of plasma clearance inevitably results in slow elimination of the drug. Our data show that half life is independent of initial plasma concentration. Earlier studies may therefore have failed to follow plasma drug concentrations for sufficient time after administration ceased and may have suffered from loss of accuracy in plasma almitrine estimations at the low drug concentrations that would be expected several days after a single dose or a few doses. A long half life implies that a long period is necessary to attain steady state plasma concentrations and carries a risk of drug accumulation. Drug intolerance would resolve only slowly after 
treatment is stopped; new dosage schedules may be required. Nevertheless, many of our patients had drug concentrations above the therapeutic range without evidence of side effects, so close monitoring of drug concentrations may not be strictly necessary.

A curvilinear association between plasma almitrine concentration and increase in $\mathrm{PaO}_{2}$ has been found after a single oral dose of almitrine, with no further increase in $\mathrm{PaO}_{2}$ with plasma almitrine concentrations above $150 \mathrm{ng} /$ $\mathrm{ml} .{ }^{18}$ In our study concentrations greater than $200 \mathrm{ng} / \mathrm{ml}$ were not associated with further increases in $\mathrm{PaO}_{2}$ and several patients had concentrations well above this figure. A correlation between plasma almitrine concentration and increased hypoxic respiratory drive after intravenous infusions of almitrine has been observed in normal subjects, though other studies have failed to relate drug concentrations to blood gas improvement, resting ventilation, or stimulation of hypoxic respiratory drive. ${ }^{19-21}$ The apparent dissociation between plasma drug concentrations and response may be due to the small amount of free drug in the blood by comparison with total plasma concentrations (almitrine is more than $99.5 \%$ protein bound), or to selective tissue uptake at the site of action.

The mean maximal increase in $\mathrm{PaO}_{2}$ in the chronic study, $0.7 \mathrm{kPa}$, is similar to the improvements of $0.5-1.3 \mathrm{kPa}$ attained over several months in patients with stable hypoxic obstructive airways disease not having domiciliary oxygen. ${ }^{22} 23 \mathrm{We}$ found no association between initial $\mathrm{PaO}_{2}$ and the increase in $\mathrm{PaO}_{2}$ with almitrine, though others have shown that the effect of the drug diminishes as gas tensions approach normal. ${ }^{24}$ Almitrine produced a significant improvement in $\mathrm{PaO}_{2}$ with only a small (non-significant) reduction in $\mathrm{PaCO}_{2}$, which is in accordance with previous reports. ${ }^{102}$ If the improvement in $\mathrm{PaO}_{2}$ occurred only through increased alveolar ventilation a concomitant fall in $\mathrm{PaCO}_{2}$ might have been expected. Changes in external ventilation are often insufficient to account for blood gas improvements, ${ }^{2024}$ though small changes may be difficult to measure accurately. Alternatively, almitrine may improve ventilation-perfusion $(\dot{V} / \dot{Q})$ relationships, especially as it is known to be vasoactive in the lung. ${ }^{1625}$

In the acute study we examined the change in $\mathrm{PaO}_{2}$ and $\mathrm{PaCO}_{2}$, measured at three oxygen flow rates, in response to varying blood concentrations of almitrine. The curves obtained suggest that the effect of almitrine became less as the subjects approached normoxia. Consequently, a patient receiving $2 \mathrm{l} / \mathrm{min}$ oxygen with a plasma almitrine concentration within the therapeutic range may expect an increment of up to $2 \cdot 2 \mathrm{kPa}$, but this will diminish as $\mathrm{PaO}_{2}$ rises. No effect on $\mathrm{PaCO}_{2}$ was observed. The tendency for high flow oxygen therapy to cause a rise in $\mathrm{PaCO}_{2}$ has long been recognised, the established explanation being that removal of hypoxic drive in patients with chronic hypercapnia causes alveolar ventilation to fall. ${ }^{6}$ In these circumstances the use of respiratory stimulants would be appropriate. If, however, the exacerbation of hypercapnia is due to further deterioration in $\dot{V} / Q$ matching, the use of such drugs would be illogical.

Our patients were in a stable condition. It has been suggested that patients with chronic obstructive lung disease respond differently to oxygen when they are stable and when they are in acute respiratory failure, because $\mathrm{PaCO}_{2}$ rises more in the latter conditions. ${ }^{26}$ Our five patients on placebo showed a mean rise of $\mathrm{PaCO}_{2}$ of $1 \cdot 1$ $\mathrm{kPa}$ when oxygen delivery was increased from 2 to $6 \mathrm{l} / \mathrm{min}$ from a baseline already within the hypercapnic range. Others have found that the rise in $\mathrm{PaCO}_{2}$ with oxygen therapy in patients with stable chronic obstructive lung disease correlates well with the initial degree of hypoxaemia and hypercapnia. ${ }^{27}$ It therefore seems likely that the response of our subjects to high flow oxygen when stable would reasonably reflect their response during an acute exacerbation. In this study almitrine caused an increase in $\mathrm{PaO}_{2}$, but did not significantly alter $\mathrm{PaCO}_{2}$. It is not known whether the drug acts in a similar way during acute exacerbations of chronic obstructive lung disease, when high oxygen flow rates are needed to achieve an adequate $\mathrm{PaO}_{2}$. In common with other workers, we found the effect of almitrine to diminish as normoxia was approached. ${ }^{24}$ Almitrine would probably be useful in an acute exacerbation of chronic obstructive lung disease only if the $\mathrm{PaO}_{2}$ did not reach the normal range with the use of oxygen therapy alone.

Almitrine did not modify the rise in $\mathrm{PaCO}_{2}$ seen with high oxygen flow rates. This, together with the findings of the chronic study, suggests that at least some of the improvement in $\mathrm{PaO}_{2}$ was brought about by mechanisms other than increased alveolar ventilation, such as improvements in $\dot{V} / Q$ matching. ${ }^{16} 25$

Our study suggests that the increase in $\mathrm{PaO}_{2}$ with almitrine is maintained over three months in patients with hypoxic cor pulmonale receiving long term domiciliary oxygen. There was no accompanying change in arterial $\mathrm{PCO}_{2}$. The long half life of the drug means that dosage schedules may need to be revised. In patients with chronic obstructive lung disease receiving long term oxygen who cannot attain a $\mathrm{PaO}_{2}$ of at least $8 \mathrm{kPa}$ without excessive hypercapnia supplemental almitrine bismesylate may be a useful additional treatment. The acute study confirmed the effects of almitrine and oxygen to be additive in increasing $\mathrm{PaO}_{2}$ in patients with chronic obstructive lung disease. The effect of almitrine diminishes as $\mathrm{PaO}_{2}$ approaches normal levels, but again no effect on $\mathrm{PaCO}_{2}$ could be found.

TWE was supported by Trent Regional Health Authority. We thank Servier Laboratories (UK) for performing estimations of blood almitrine concentrations.

Full tables of results for this study may be obtained on request. 
1 Fishman AP. Chronic cor pulmonale. Am Rev Respir Dis 1976;114:775-94

2 Middleton HL, Peake MD, Howard P. Hypoxia in chronic obstructive bronchitis. Thorax 1979;34:213-6.

3 Medical Research Council Working Party. Long term domiciliary oxygen therapy in chronic hypoxic cor pulmonale complicating chronic bronchitis and emphysema. Lancet 1981;i:681-5.

4 Nocturnal Oxygen Therapy Trial Group (NOTT). Continuous or nocturnal oxygen therapy in hypoxaemic chronic obstructive airways disease: a clinical trial. Ann Intern Med 1980;93:391-8.

5 Evans TW, Waterhouse J, Howard P. Clinical experience with the oxygen concentrator. BrMed J 1983;287:459-61.

6 Gelb AF, Klein E, Schiffman P, Lugliani R, Aronstan P. Ventilatory response and drive in acute and chronic obstructive pulmonary disease. Am Rev Respir Dis 1977; 16:9-16.

7 Bickerman HA, Chusid EL. The case against respiratory stimulants. Chest 1972;58:53-6.

8 Howard P. Almitrine bismesylate. Bull Eur Physiopathol Respir 1984;20:99-103.

9 Arnaud F, Bertrand A, Charpin J, Cretien J, Decroux F, Guerrin F. Almitrine bismesylate in long term treatmen of patients with chronic bronchitis at the stage of chronic piratory insuf placebo-controlled study. Bull Eur Physiopathol Respir 1982;18 (suppl 4):373-82.

10 Bell RC, Mullins RC III, West LG, Bachand RT, Johanson WG, Jr. The effect of almitrine bismesylate on hypox aemia in patients with COPD. Ann Intern Med 1986 105:342-6.

11 Baune A, Bromet N, Courte S, Voisin C. Trace determination of almitrine in plasma by gas-liquid chromatography using a nitrogen phosphorus detector. J Appl Chromatog Biomed 1981;223:219-24.

12 Aubert Y, Baune A, Courte S, Gullaudeux J. Pharmacocinatique du bismesilate d'almitrine chez l'homme. Correlations entre les taux plasmatiques et les effets phartions entre les taux plasmatiques et les effets pharmacodynamiques.

13 Baker RJ, Nelder JA. The GLIM system manual. Release 3. Oxford Numerical Algorithm Group, 1978

14 Snedecor GW, Cochrane WG. Statistical methods. 6th ed. Ames: Iowa State University Press, 1967

15 McLeoud CM, Thomas RW, Bartley EA, Parkhurst GW, Bachard RT. Effects and handling of almitrine bis- mesylate in healthy subjects. Eur $J$ Respir Dis 1983;64 (suppl 126):275-89.

16 Neaije R, Melot C, Mols P, et al. Effects of almitrine in decompensated chronic respiratory insufficiency. Bull Eur Physiopathol Respir 1981;17:153-61.

17 Powles ACP, Tuxen DV, Mahood CB, Pugsley SO, Campbell EJM. The effects of intravenously administered almitrine, a peripheral chemoreceptor agonist, on patients with chronic airflow obstruction. Am Rev Respir Dis 1983;127:284-9.

18 Radermecker M, Bury T. Dose-effect study following repeated oral administrations of almitrine bismesylate in COPD patients [abstract]. Am Rev Respir Dis 1986; 133:A99.

19 Stanley NN, Galloway JM, Gordon B, Pauly N. Increased respiratory chemosensitivity induced by infusing almitrine intravenously in healthy man. Thorax 1983; 38:200-4.

20 Simmoneau G, Meignan M, Denjean A, Raffestin B, Harf A Prost JF. Cardiopulmonary effects of a single oral dose of almitrine at rest and on exercise in patients with hypoxic chronic airflow obstruction. Chest 1986;89:174-9.

21 Stradling JR, Barnes P, Pride NB. The effects of almitrine on the ventilatory response to hypoxia and hypercapnia in normal subjects. Clin Sci 1982;63:401-2.

22 Prefaut $C$, Bourgouin-Karaouni D, Ramonatxo $M$, Miche FB. Blood gases and pulmonary haemodynamic follow up during a one year double-blind trial of almitrine bisduring a one year double-blind trial of almitrine bismesylate therapy in COPD
Respir Dis 1985;131:A71.

23 Suggett AJ, Proctor A, Smyllie H, Peake MD, Cayton RM, Howard $P$. Which patients benefit from long-term almitrine? [abstract]. Thorax 1986;41:224.

24 Stradling JR, Nicholl GG, Cover D, Davies EE, Hughes JMB, Pride NB. The effects of oral almitrine on pattern of breathing and gas exchange in patients with obstructive pulmonary disease. Clin Sci 1984;66:174-9.

25 Melot C, Naeije R, Rothschild T, Mertens P, Mols P, Hallemans $R$. Improvement in ventilation-perfusion matching by almitrine in COPD. Chest 1983;83:528-33.

26 Rudolph M, Banks RA, Semple SJG. Hypercapnia during oxygen therapy in acute exacerbations of chronic respiratory failure. Lancet 1977;ii:483-6.

27 Bone RC, Pierce AK, Johnson RL. Controlled oxygen administration in acute respiratory failure in chronic obstructive pulmonary disease. Am J Med 1978;65: 896-902. 